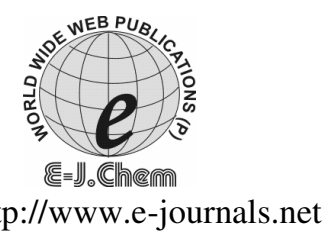

ISSN: 0973-4945; CODEN ECJHAO
E-Journal of Chemistry
2010, 7(2), 600-604

\title{
A Validated RP-HPLC Method for the Estimation of Levetiracetam in Bulk and Pharmaceutical Formulations
}

\author{
A.LAKSHMANA RAO* and V.NAGA JAHNAVI \\ Department of Pharmaceutical Analysis, \\ Shri Vishnu College of Pharmacy, Vishnupur, Bhimavaram- 534 202, A.P., India. \\ dralrao@gmail.com
}

Received 11 September 2009; Accepted 5 November 2009

\begin{abstract}
A rapid and sensitive high performance liquid chromatographic method was developed for the estimation of levetiracetam in bulk and pharmaceutical formulations. Levetiracetam was chromatographed on a reverse phase $\mathrm{C}_{18}$ column in a mobile phase consisting of $0.05 \mathrm{M} \mathrm{KH}_{2} \mathrm{PO}_{4}$ buffer (pH 3.0 adjusted with orthophosphoric acid) and methanol in the ratio 70:30 v/v. The mobile phase was pumped at a flow rate of $1.2 \mathrm{~mL} / \mathrm{min}$. with detection at $210 \mathrm{~nm}$. The detector response was linear in the concentration of $20-120 \mu \mathrm{g} / \mathrm{mL}$. The limit of detection and limit of quantification was found to be 0.0104 and $0.0317 \mu \mathrm{g} / \mathrm{mL}$, respectively. The intra and inter day variation was found to be less than $1 \%$. The mean recovery of the drug from the solution containing $100 \mu \mathrm{g} / \mathrm{mL}$ was $100.038 \mu \mathrm{g} / \mathrm{mL}$. The proposed method is simple, fast, accurate, precise and reproducible hence can be applied for routine quality control analysis of levetiracetam in bulk and pharmaceutical formulations.
\end{abstract}

Keywords: Levetiracetam, RP-HPLC, Estimation, Tablets.

\section{Introduction}

Levetiracetam is a novel antiepileptic drug which is structurally dissimilar to other antiepileptic drugs. It is chemically, $(\alpha S)$ - $\alpha$-ethyl-2-oxo-1-pyrrolidineacetamide ${ }^{1}$. This is a structural analog of piracetam, which binds to a synaptic vesicle protein SV2A. This is believed to impede nerve conduction across synapses. The precise mechanism by which levetiracetam exerts its antiepileptic effect is unknown. Literature survey reveals that various $\mathrm{HPLC}^{2-7}$ and LC-MS ${ }^{8-10}$ methods have been reported for the determination of levetiracetam in pure and pharmaceutical dosage forms. In this study a simple, rapid, accurate, sensitive and precise HPLC method was developed for the estimation of levetiracetam in pharmaceutical formulations. 


\section{Experimental}

Methanol of HPLC grade was purchased from E.Merck (India) Ltd., Mumbai. Potassium dihydrogen phosphate and orthophosphoric acid of AR grade were obtained from Qualigens Fine Chemicals Ltd., Mumbai. Levetiracetam was a gift sample by Orchid Chemicals \& Pharmaceuticals Ltd., Chennai. The commercially available levetiracetam tablets claimed to contain $250 \mathrm{mg}$ of drug were procured from local market.

\section{Instrumentation}

The separation was carried out on gradient HPLC system (Shimadzu) with Shimadzu binary HPLC LC 20AT pump, Shimadzu APD 20A UV-Visible absorbance detector, Spinchrom software and $\mathrm{RP}_{-\mathrm{C}_{18}}$ column $(250 \mathrm{mmx} 4.6 \mathrm{~mm}$ I.D; particle size $5 \mu \mathrm{m})$.

\section{Chromatographic conditions}

The mobile phase consisting of phosphate buffer ( $\mathrm{pH} 3.0$ adjusted with orthophosphoric acid) and methanol were filtered through $0.45 \mu$ membrane filter before use, degassed and were pumped from the solvent reservoir in the ratio of 70:30 v/v was pumped into the column at a flow rate of $1.2 \mathrm{~mL} / \mathrm{min}$. The detection was monitored at $210 \mathrm{~nm}$ and the run time was $8 \mathrm{~min}$. The volume of injection loop was $20 \mu \mathrm{L}$ prior to injection of the drug solution the column was equilibrated for at least $30 \mathrm{~min}$. with the mobile phase flowing through the system. The column and the HPLC system were kept in ambient temperature.

\section{Procedure}

Stock solution of levetiracetam was prepared by dissolving $100 \mathrm{mg}$ of levetiracetam in $100 \mathrm{~mL}$ standard volumetric flask containing $25 \mathrm{~mL}$ of mobile phase and the solution was sonicated for $20 \mathrm{~min}$. and then made up to the mark with mobile phase to get a concentration of $1 \mathrm{mg} / \mathrm{mL}$. Subsequent dilutions of this solution were made with mobile phase to get concentration of $20-120 \mu \mathrm{g} / \mathrm{mL}$. The standard solutions prepared as above were injected into the $10 \mu \mathrm{L}$ loop and the chromatogram was recorded in Figure 1.

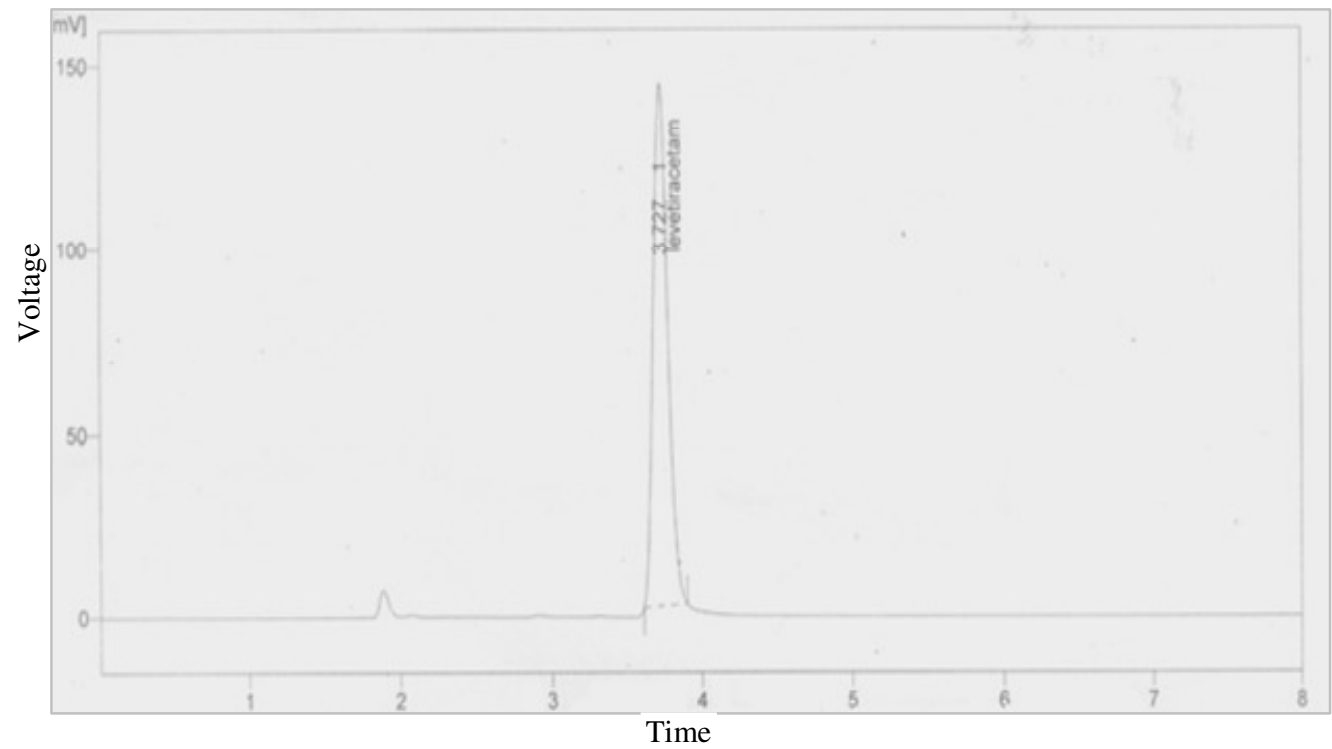

Figure 1. Typical chromatogram of levetiracetam. 
The retention time of levetiracetam was found to be $3.727 \mathrm{~min}$. The calibration curve was constructed by plotting concentration $v s$ peak area ratio. The amount of levetiracetam present in sample was calculated through the standard calibration curve. The linearity experiment was carried out in triplicate to ascertain accuracy and precision of the method. The peak area ratios of the drug vs concentration were found to be linear and the results are furnished in Table 1.

Table 1. Calibration of HPLC method for the estimation of levetiracetam.

\begin{tabular}{ccc}
\hline $\begin{array}{c}\text { Concentration of } \\
\text { levetiracetam, } \mu \mathrm{g} / \mathrm{mL}\end{array}$ & Peak area* & C.V, \% \\
\hline 20 & 204.156 & 0.932 \\
40 & 389.465 & 0.413 \\
60 & 560.390 & 0.095 \\
80 & 757.902 & 0.885 \\
100 & 947.234 & 0.729 \\
120 & 1120.473 & 0.808 \\
\hline
\end{tabular}

*Mean of five deteriminations.

Assay

Two commercial brands of tablets were chosen for testing suitability of the proposed method to estimate levetiracetam in pharmaceutical formulations. Twenty tablets each containing $250 \mathrm{mg}$ were weighed accurately and powdered. A quantity equivalent to $100 \mathrm{mg}$ of levetiracetam was weighed accurately and transferred to $100 \mathrm{~mL}$ volumetric flask with mobile phase. The contents were sonicated for $20 \mathrm{~min}$. and made up to the mark with the mobile phase. The resulting solution is filtered through a membrane filter. The solution obtained was diluted with the mobile phase so as to obtain a concentration in the range of linearity previously for the pure drug determined. Sample solution was injected under the chromatographic conditions and the chromatogram was recorded. The amount of levetiracetam present in tablet formulation was determined by comparing the peak area from the standard. The results are furnished in Table 2 .

Table 2. Assay of levetiracetam.

\begin{tabular}{cccc}
\hline Formulation & Label claim, mg & Amount found, mg & \% Amount found \\
\hline Brand-1 & 250 & 246.525 & 98.61 \\
Brand-2 & 250 & 250.05 & 100.02 \\
\hline
\end{tabular}

\section{Validation of proposed method}

Selectivity of the method was assessed on the basis of elution of levetiracetam using the above mentioned chromatographic conditions. To study the specificity, linearity, precision, accuracy, limit of detection, limit of quantitation, robustness and system suitability parameters has been validated for the determination of levetiracetam. The results are furnished in Table 3.

Table 3. Validation summary.

\begin{tabular}{ll}
\hline System suitability parameters & Results \\
\hline Theoritical plates & 6359 \\
Linearity range & $20-120 \mu \mathrm{g} / \mathrm{mL}$ \\
Correlation coefficient & 0.9998 \\
Retention time & 3.727 \\
Asymmetric factor & 1.260 \\
LOD & $0.0104 \mu \mathrm{g} / \mathrm{mL}$ \\
LOQ & $0.0317 \mu \mathrm{g} / \mathrm{mL}$ \\
\hline
\end{tabular}




\section{Specificity}

The specificity was established by preparing a levetiracetam standard at $0.5 \%$ level of test concentration and injected 5 times into HPLC system as per the test procedure.

\section{Linearity}

The standard curve was obtained in the concentration range of $20-120 \mu \mathrm{g} / \mathrm{mL}$. The linearity was evaluated by linear regression analysis using the least square method. It was found that correlation coefficient and regression analysis are within the limits.

\section{Precision}

The precision of the assay was determined in terms of intra-day and inter-day precision. The intra-day and inter-day variation in the peak area of drug solution was calculated in terms of coefficient of variation (C.V.) obtained by multiplying the ratio of standard deviation to mean with 100. The results are furnished in Table 4.

Table 4. Inter and intra day precision for levetiracetam by the proposed HPLC method.

\begin{tabular}{ccccc}
\hline Concentration of & \multicolumn{3}{c}{ Concentration of levetiracetam found on } \\
\cline { 2 - 5 } levetiracetam, $\mu \mathrm{g} / \mathrm{mL}$ & \multicolumn{2}{c}{ Intraday } & \multicolumn{2}{c}{ Interday } \\
\hline & Mean(n=5) & C.V.\% & Mean $(\mathrm{n}=5)$ & C.V.\% \\
40 & 40.201 & 0.25267 & 40.188 & 0.25702 \\
80 & 80.720 & 0.05684 & 80.412 & 0.5917 \\
120 & 118.729 & 0.741149 & 118.779 & 0.2825 \\
\hline
\end{tabular}

\section{Limit of detection (LOD) and limit of quantitation (LOD)}

The LOD and LOQ for levetiracetam were predicted basing on the parameters of standard error of estimate and slope, calculated from linearity of the response data of levetiracetam.

\section{Robustness}

The robustness was checked by changing the temperature to $30{ }^{\circ}$ and $35{ }^{\circ} \mathrm{C}$ and the method suits best.

\section{Accuracy}

The accuracy of the HPLC assay method was assessed by adding known amount of drug solution to a drug solution of known concentration and subjecting the samples to the proposed HPLC method. The recovery studies were replicated 3 times. The accuracy was expressed in terms of recovery and calculated by multiplying the ratio of measured drug concentration to the expected drug concentration with 100 so as to give the percentage recovery. The results are furnished in Table 5 .

Table 5. Recovery of levetiracetam using proposed HPLC method.

\begin{tabular}{ccc}
\hline $\begin{array}{c}\text { Amount of drug } \\
\text { added, } \mu \mathrm{g} / \mathrm{mL}\end{array}$ & $\begin{array}{c}\text { Mean }( \pm \mathrm{SD}) \text { amount } \\
\text { found, } \mu \mathrm{g}(\mathrm{n}=5)\end{array}$ & $\begin{array}{c}\text { Mean \% of recovery } \\
(\mathrm{n}=5)\end{array}$ \\
\hline 20 & $20.005( \pm 0.362)$ & 100.028 \\
60 & $60.00( \pm 0.062)$ & 100.00 \\
100 & $100.048( \pm 0.395)$ & 100.048 \\
\hline
\end{tabular}




\section{Results and Discussion}

By applying the proposed method, the run time of the method was set at $8 \mathrm{~min}$ and levetiracetam appeared on the typical chromatogram at $3.727 \mathrm{~min}$., which indicates a good base line. When the same drug solution was injected 5 times, the retention time of the drug was same. Linearity range was observed in concentration range of $20-120 \mu \mathrm{g} / \mathrm{mL}$. The regression equation of levetiracetam concentration over its peak area ratio was found to be $\mathrm{Y}=0.10845 \mathrm{X}-1.92745(\mathrm{r}=0.9998)$ where $\mathrm{Y}$ is the peak area ratio and $\mathrm{X}$ is the concentration of levetiracetam $(\mu \mathrm{g} / \mathrm{mL})$. The proposed HPLC method was also validated for intra-day and inter-day variation. The coefficient of variation in the peak area of the drug for 5 replicate injections was found to be less than $1 \%$. The asymmetry factor was found to be 1.260 , which indicated asymmetric nature of peak. The number of theoretical plates was found to be 6359 , which indicates efficient performance of the column. The limit of detection and limit of quantitation was found to be $0.0104 \mu \mathrm{g} / \mathrm{mL}$ and $0.0317 \mu \mathrm{g} / \mathrm{mL}$, indicates the sensitivity of the method. To optimize the chromatographic conditions, various combinations of phosphate buffer with and methanol were tested. The use of phosphate buffer and methanol in the ratio of 70:30 v/v resulted in peak with good shape and resolution. The high percentage of recovery of levetiracetam ranging from 100.028 to 100.048 indicates that the proposed method is highly accurate. No interfering peaks were found in the chromatogram indicating that excipients used in tablet formulation did not interfere with the estimation of the drug by proposed HPLC method.

\section{Conclusion}

The proposed HPLC method was found to be simple, rapid, precise, accurate and sensitive for the determination of levetiracetam in pharmaceutical dosage forms. Hence, this method can easily and conveniently adopt for routine analysis of levetiracetam in pure and its pharmaceutical formulations.

\section{References}

1. The Merck Index, $13^{\text {th }}$ Edn., Merck \& Co., Inc., Whitehouse Station, NJ, 2001, p.978.

2. Manuela C, Susan M, Fiorenzo A, Roberto R and Agostino B, J Chromatogr B., 2008, 873(1), 129.

3. Appala Raju N, Venkateswara Rao J, Vanitha Prakash K, Mukkanti K and Srinivasu K. E- Journal of Chemistry, 2008, 5(S2), 1098.

4. Valarmathy J, Samueljoshua L, Rathinavel G, Selvin Thanuja C and Sivakumar T, Research J Pharm and Tech., 2008, 1(3), 395.

5. Martens Lobenhoffer J and Bode Boger S M, J Chromatogr B., 2005, 819, 197.

6. Ratnaraj N, Doheny Helen C and Patsalos Philip N, Ther Drug Monit., 1996, 18(2), 154.

7. Vermeij A C and Edelbroek P M, J Chromatogr B., 1994, 662, 134.

8. Kamal Matar M, J Pharm Biomed Anal., 2008, 48(3), 822.

9. Saravanan G, Jyothi G, Suresh Y, Annerao A, Ramakrishna M, Yogeshwar Reddy M and Ravibabu B, Chromatographia, 2008, 67, 173.

10. Tiedong Guo, Lisa Oswald M, Damodara Rao M and Steven Soldin J, Clinica Chimica Acta, 2007, 375, 115. 


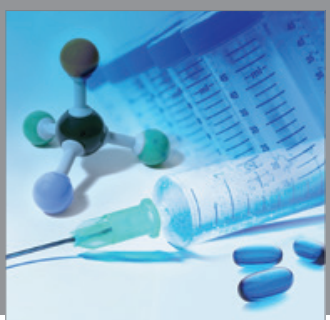

International Journal of

Medicinal Chemistry

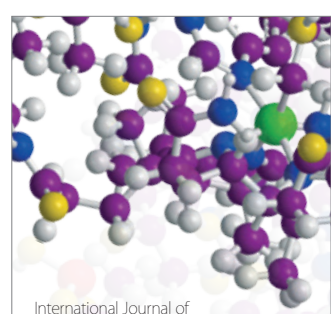

Carbohydrate Chemistry

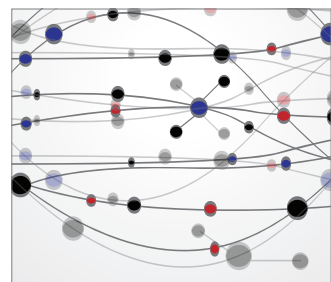

The Scientific World Journal
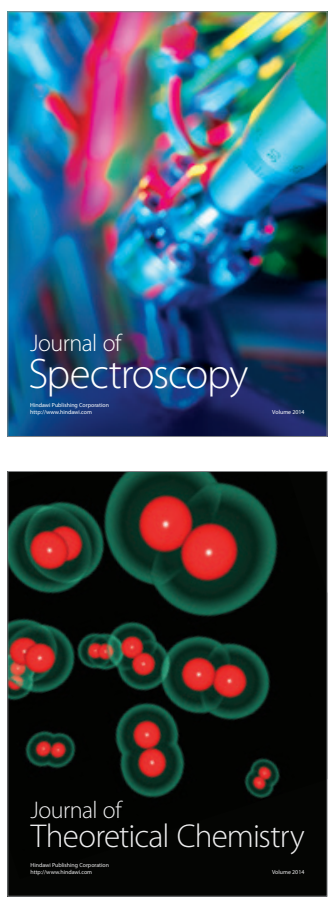
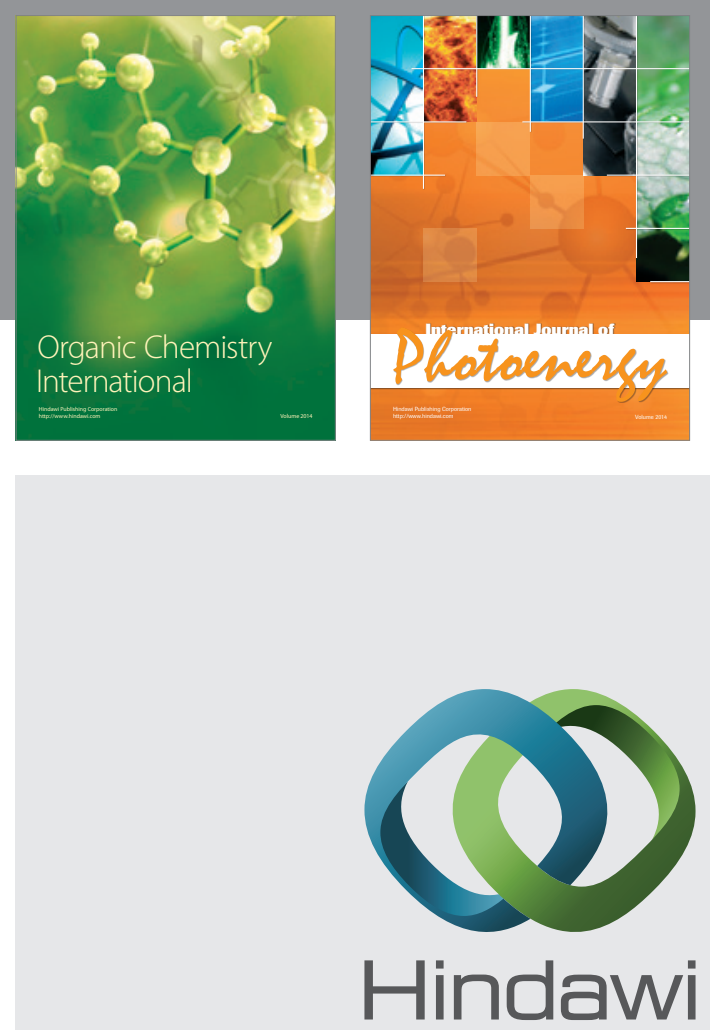

Submit your manuscripts at

http://www.hindawi.com
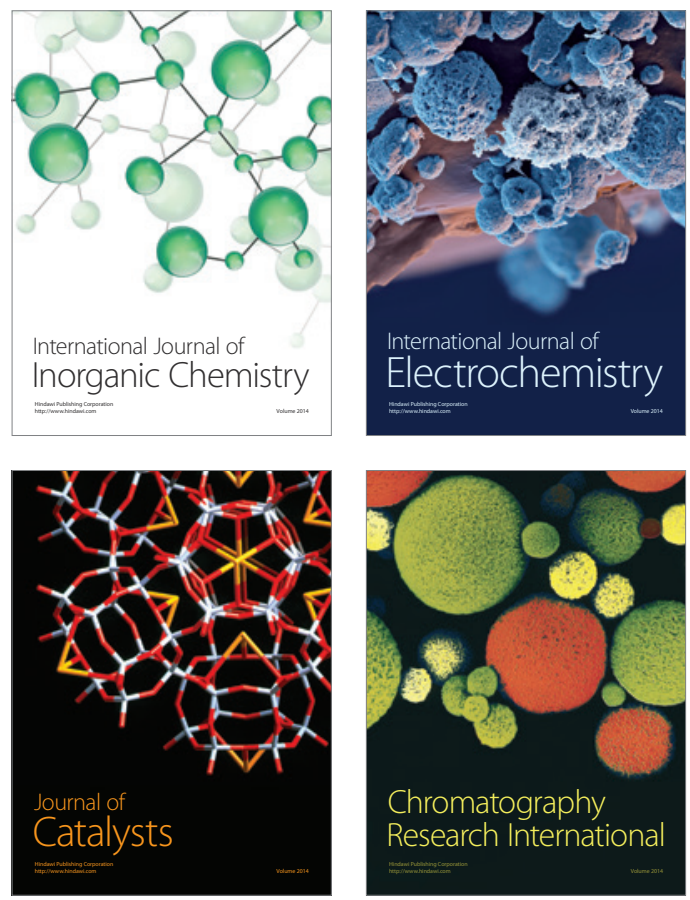
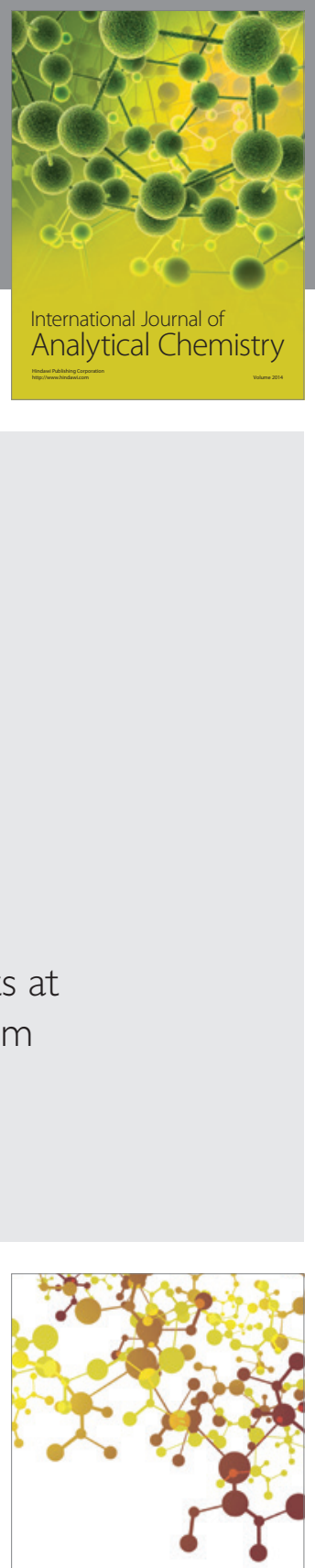

Journal of

Applied Chemistry
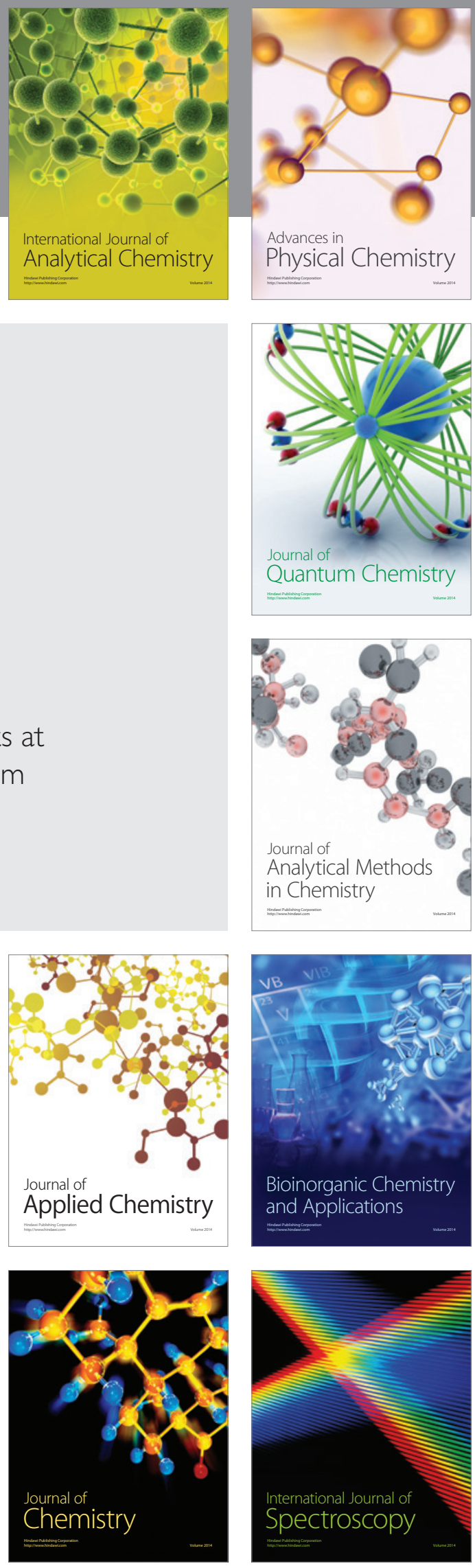